\title{
Alberto Flores Galindo, intelectual de izquierda
}

\author{
Osmar Gonzales Alvarado \\ Universidad Nacional Mayor de San Marcos, Lima, Perú \\ osmar.gonzales@gmail.com
}

\begin{abstract}
RESUMEN
El presente ensayo está ubicado temporalmente en el Perú post-oligarquico de los años 70, particularmente en el escenario intelectual y político que se abrió como expresión de una nueva época que emergía. En este contexto se produce una renovación de las ideas, emprendida por una generación de jóvenes intelectuales de izquierda comprometidos en dar forma a una nueva sociedad, quienes combinaban una profunda reflexión teórica y acción política y que renovarían decisivamente las ciencias sociales y la historia. En esta nueva generación de intelectuales destacaría y sería reconocido ampliamente Alberto Flores Galindo como el intelectual, historiador e ideólogo más importante.
\end{abstract}

Palabras clave: Alberto Flores Galindo, intelectual, generación del 68, izquierda, historiador ideólogo

\section{Alberto Flores Galindo, left -wing intelectual}

\begin{abstract}
This essay is located temporally in the post oligarchic Peru, in the 70's, especially in the politic and intellectual scenario that was the result of a new period. In this context took place the renewal of some ideas, it was established for a generation of left -wing young intellectuals engaged in creating and shaping a new society. They got a combination of a deep theoretical reflection and a political action that would significantly renewed social sciences and history. In this new generation of intellectuals would be recognized and well known, Alberto Flores Galindo, as an intellectual, historian and most important ideologist.
\end{abstract}

KeYwords: Alberto Flores Galindo, intellectual, 68s generation, left -wing, historian, ideologist 


\section{Introducción}

El Perú post-oligárquico marcado a fuego por las reformas militares de los años setenta fue un escenario abierto en el que se ofrecían posibilidades tanto en la reconfiguración de la vida social como en la renovación de la reflexión intelectual indispensable para interpretar la nueva época que emergía. ${ }^{1}$

Especialmente las ciencias sociales y la historia contribuyeron a entender el nuevo país que se constituía con el surgimiento de nuevos actores sociales, y a tratar de avizorar qué se debía hacer para moldear el futuro. Así, en los retos que aparecían entre el pasado y el porvenir, la política ocuparía un lugar de crucial importancia en la vida social. En ese momento histórico surgiría una juventud con voluntad de dar forma a una nueva sociedad luego de destruido el orden oligárquico. Fundamentalmente de izquierda, estos jóvenes trataron de unir reflexión teórica con acción política, pero con una política diferente a la que había prevalecido antaño y propia de las esferas oficiales: la nueva política ya no se centraría en las élites y grupos privilegiados, sino en el pueblo, en los sectores usualmente excluidos. Surgiría entonces el intelectual comprometido de izquierda.

Dentro de esa cohorte de jóvenes destacaría Alberto Flores Galindo, ejemplar en el propósito mencionado de aunar reflexión y compromiso político, labrando una trayectoria como ideólogo que sería reconocida tanto por simpatizantes como por rivales ideológicos.

\section{Importancia de un historiador ideólogo}

Alberto Flores Galindo es uno de los más importantes historiadores de la generación post-oligárquica, y en eso hay consenso, más allá de las discrepancias, principalmente ideológicas, que suscita su obra. Gonzalo Portocarrero califica a Flores Galindo y a su obra como una hazaña, fruto del heroísmo:

La elaboración de la utopía andina fue una hazaña intelectual que implicó mucha ansiedad y sacrificios. Alberto Flores Galindo se había impuesto como deber imaginar la unidad del Perú, la ruptura de ese orden colonial desvertebrado y sin alternativa. En la línea abierta por Mariátegui y Arguedas, identificó en lo andino el elemento cimentador de la nueva nacionalidad. Su aporte fue el identificar los derroteros que habían permitido a lo andino resistir, abrirse paso en medio de la negación colonial y republicana (Portocarrero, 2005).

\footnotetext{
1 Agradezco los comentarios que el profesor Ramón León hizo a la versión anterior de este artículo que me ayudaron a mejorarlo.
} 
En esta mirada coincide Edgar Montiel, ${ }^{2}$ entre otros. Carlos Aguirre (2007) destaca la importancia que tuvo en nuestro historiador ideólogo la palabra escrita a la que tanto contribuyó a expandir y legitimar. Augusto Ruiz Zevallos (2011) ha realizado un excelente estudio sobre su proyecto político. Carlos Iván Degregori lo reconoce como uno de los mejores exponentes de la intelectualidad peruana: ...fue uno de los intelectuales que permitió soñar a los jóvenes de varias generaciones que otro mundo, o al menos otro país, era posible» (Degregori, 2005: 3). Nelson Manrique lo califica como el historiador más importante de las últimas décadas, que «reconocía el papel que podían jugar los intelectuales, pero llamaba al mismo tiempo a pensar el quehacer intelectual de otra manera» (Manrique, 2005: 11). Igualmente, Manuel Burga (2019), conociendo de cerca cómo fue el proceso de elaboración de sus ideas, destaca su trabajo historiográfico e intelectual y lo define como uno de los intelectuales más influyentes del Perú (Burga, 2005).

Flores Galindo nació en 1949 y murió en 1990. En 1974 publicó su primer libro, Los mineros de la Cerro de Pasco. Es decir, su producción académica cubrió solo 15 años, lo que nos dice de su precocidad intelectual y de la dedicación que puso para dar forma a una obra nutrida e importante, que se compone de libros, ensayos, artículos de divulgación, entrevistas; de participación en mesas redondas, en conferencias especializadas y de divulgación, aparte de ser profesor universitario.

José Ragas y Jorge Valdez (2009) llaman la atención sobre aspectos de la vida de Flores Galindo con anécdotas que nos presentan a un personaje aventurero, muy distinto al serio historiador que se conoce por su participación en la esfera pública. Por eso, sostienen, no debe sorprender que: «el historiador más prometedor de su generación también haya sido un joven impetuoso, irresponsable y curioso, que llegó hasta Chile tirando dedo y que lamentó haber vendido su biblioteca para comprarse una motocicleta, la misma que luego estrellaría en un accidente».

Como he mencionado, Flores Galindo fue un intelectual precoz, como han habido otros en nuestra historia. El caso más relevante puede ser el del también historiador José de la Riva Agüero, quien entre los 19 y 24 ańos dio a conocer dos trabajos seminales en los estudios literarios e historiográficos: Carácter de la literatura del Perú independiente (1905) y La Historia en el Perú (1910). Aunque también podemos mencionar a su compañero generacional y amigo personal, Francisco García Calderón, al igual que a otros estudiosos como Jorge Basadre, Luis Alberto Sánchez o Raúl Porras Barrenechea, por citar algunos ejemplos conocidos.

2 Afirma Montiel: «En la vida de Flores Galindo hay algo que se puede llamar heroísmo. Comenzó joven su trabajo intelectual, sus lecturas y viajes largos por Cusco. Siempre con una actitud cooperativa. Su trabajo en el Centro Bartolomé de Las Casas fue una donación de su tiempo. Y sus escritos en revistas y libros tuvieron una notable acogida, escritos con una prosa clara, comprometida, seguro de lo que quería decir. Su libro Buscando un Inca es una obra de referencia en una bibliografía sobre el Perú. Y se fue temprano». Comunicación personal: jueves 29 de agosto de 2019. 
Flores Galindo se propuso comprender, escribir e intervenir en la historia de «los de abajo». Esta preocupación fue pre ideológica, es decir, antes de asumirse como un intelectual de izquierda, y provino desde sus ańos de escolar en el colegio La Salle, cuyos profesores inculcaban en sus alumnos la preocupación por los pobres, haciéndoles cumplir labores de proyección social, participando en campañas de alfabetización, por ejemplo. En la universidad esta sensibilidad se afianzó con el contacto que tuvo con su profesor, el padre Gustavo Gutiérrez, quien formuló las ideas básicas de la teología de la liberación, basada en la preocupación principal por los pobres. También influyó en su perspectiva histórica Heraclio Bonilla, profesor con el que luego tendría importantes debates sobre el tema de la Independencia.

Cuando ingresó a la Universidad Católica, Flores Galindo inició sus estudios partiendo de una formación tradicional sobre la historia y la forma de interpretar los problemas nacionales, pero no pasó muchos tiempos para que la cuestionara, pues no tomaba en consideración el papel de las clases populares en el proceso nacional y se centraba en los personajes destacados, además porque el mundo andino no existía como una preocupación central. Posteriormente, sus estudios en Francia contribuyeron a cimentar su vocación de historiador así como a establecer su identificación ideológica. Asimiló con ansias las enseńanzas de profesores de la talla de Pierre Vilar, François Furet, Ruggiero Romano, Ferdinand Braudel, entre otros. Las mentalidades, la larga duración, la vida cotidiana, la región como espacio geográfico y social ${ }^{3}$ fueron algunos de los conceptos que trajo al Perú y que imprimiría en sus escritos posteriormente. Las cartas que dirigió a Manuel Burga son una excelente evidencia de cómo vivió su experiencia europea, entre el sentimiento de nostalgia por la lejanía física y la emoción por el nuevo conocimiento (en libros y en la propia vida) que iba adquiriendo (Burga, 2010). ${ }^{4}$

\section{La obra intelectual siempre en movimiento}

Nuestro historiador fue dueńo de una escritura elegante y cautivante que no impedía la transmisión firme de su postura, siendo incluso irónico o sarcástico cuando se enfrentaba a sus adversarios ideológicos.

Uno de los aspectos más atractivos de los trabajos de Flores Galindo fue que en su narrativa el lector casi podía observar a los personajes de la historia como seres vivos,

3 Su estudio Arequipa y el sur andino, Ensayos de Historia regional, Siglos XVIII-XX, de 1976, ejemplifica su preocupación por estos temas.

4 Gracias a una beca otorgada por el gobierno francés, Flores Galindo durante los ańos 1972-1974 en la École des Hautes Études en Sciences Sociales, París. Siendo su asesor Ruggiero Romano, presentó su tesis doctoral titulada Autocratie et plebe, Lima 1760-1830 que luego, en 1984, publicaría bajo el título de Aristocracia y Plebe. Lima, 1760-1830. Estructura de clases y sociedad Colonial. 
adentrarse en sus personalidades, conocer sus tribulaciones, saber de sus decisiones en medio de las encrucijadas que le presentaban sus circunstancias. Y esta fascinación cautivación acrecentaba cuando nos permitía descubrir el mundo de los silenciados por aquella historia tradicional usualmente más preocupada por los personajes célebres, y enfocar el lente en los pobres, en los marginados y olvidados.

Igualmente, Flores Galindo no creía en que las obras escritas debían ser inamovibles, estáticas, principalmente las suyas. Por el contrario, sus textos, de manera especial, los trataba como productos siempre plausibles de ser modificados, corregidos, ampliados, mejorados. Por ello, es difícil encontrar reimpresiones de sus títulos, más probable es encontrar reediciones, pues su lectura voraz y el constante incremento de conocimientos hacía que Flores Galindo estuviera en permanente estado de actualización de sus propios planteamientos. Esto hace un poco más laborioso el trabajo del historiador de ideas, pues siguiendo la pista de un mismo título puede encontrar una ruta conceptual o de puntos de vista dinámicos en nuestro autor, que se ramifica copiosamente. Más complejo resulta el esfuerzo es si intenta abarcar toda su obra. En este sentido, un trabajo sumamente recomendable es el de Augusto Ruiz Zevallos (2011), que a la manera del historiador argentino Elías José Palti, rastrea los orígenes y evolución de las principales categorías que utilizó Flores Galindo en sus investigaciones y reflexiones.

Otro aspecto en el que Flores Galindo desplegó su carácter pedagógico fue el de la clase universitaria. En ella no solo transmitía el conocimiento bibliográfico indispensable sino que añadía dos cuestiones cruciales: su opinión crítica de los textos que abordaba, y los avances de sus propias investigaciones. Ello hacía que sus sesiones se convirtieran para sus alumnos en estímulos constantes por el descubrimiento de nuevas ideas. En el aula, Flores Galindo ejercía pleno dominio de sus fichas, que constituían las columnas de sus siempre agudas explicaciones. Pero al mismo tiempo era severo con los errores y deslices de los estudiantes, no para desmoralizarlos, sino para que corrigieran sus ligerezas. Prueba de ello es que no tenía reparos ni prejuicios en citar las monografías que sus estudiantes le presentaban en los cursos. Era un reconocimiento y un estímulo, simultáneamente. Una manera democrática de entender la actividad académica y de construir el campo intelectual.

\section{La generación «del 68»y Alberto Flores Galindo}

Por otra parte, Flores Galindo tenía plena conciencia de su identidad generacional. Esto se manifiesta en su artículo "La generación del 68» en el que, desde su postura de izquierda analiza a la misma ubicándose simultáneamente como crítico y como sujeto analizado. Nuestro historiador se definía a sí mismo como un intelectual de izquierda, pero sobre todo un ideólogo. A propósito del tema generacional, sostiene que una 
generación cuando se encuentran acontecimientos y vivencias con proyectos y actitudes cohesionadores de coetáneos. Así, la palabra generación, dice tomando a Pablo Macera, «se limita, por lo común, a los profesionales de la ideología, es decir, a los intelectuales» (Flores Galindo, 1987a: 103).

Al parecer de Flores Galindo, es el ideólogo -que constituye, transmite y legitima una idea o un proyecto político- la principal figura que el sujeto de ideas podría encarnar. Y él mismo se concebía como ideólogo, ideólogo de izquierda. Ya diferentes autores lo han calificado como un intelectual comprometido o intelectual público de izquierda, y con toda razón. Siguiendo con su análisis de la generación del 68, nuestro autor afirma que el aporte de la nueva izquierda fue el clasismo, que expresó la lucha política y social de las clases trabajadoras, a las que la izquierda marxista buscaba despertar la conciencia de clase por medio de los intelectuales precisamente — quienes conocían los textos marxistas aunque de una manera literal, sostiene Flores Galindo-, autoproclamados como conductores y estableciendo una relación jerárquica con los trabajadores que no siempre fue aceptada por estos (Flores Galindo, 1987a: 105-106). Guillermo Rochabrún deriva que para Flores Galindo la suya fue una "generación fallida» en tanto proclamó la necesidad inevitable de llevar a cabo la revolución, pero que nunca realizó (Rochabrún, 2007: 454).

Para nuestro personaje, solo había lugar para el compromiso por el cambio social (lo que recuerda al José Carlos Mariátegui de La escena contemporánea, que solo relevaba el papel del intelectual revolucionario). Ello lo llevaba a considerar que todo aquello que no contribuía a ese objetivo era fútil. Al respecto, puedo contar una anécdota personal. Cuando a mediados de los ańos ochenta estaba escribiendo mi libro sobre los arielistas, Sanchos fracasados (Gonzales, 1996), luego de leer algunos de mis adelantos, consideró que estaba perdiendo el tiempo, lo que me sorprendió, debo admitirlo. Pero poco tiempo después, me invitó a ofrecer que ofrezca una exposición sobre mi investigación en el local de la revista Márgenes. Lo que deseo destacar es la rápida reacción de Flores Galindo, que implicaba generosidad intelectual, pero sobre todo personal. Considero que esta anécdota revela la tensión entre el ideólogo y el historiador, la búsqueda del difícil equilibrio que Flores Galindo buscaba preservar.

Volviendo a su texto, y desde la perspectiva de análisis sobre las generaciones de Karl Mannheim (1952), es necesario señalar que la denomina así — «del 68», generación que prefiero denominar post oligárquica (Gonzales, 1999) — porque el «contacto fresco» que vivieron los jóvenes de fines de los años sesenta fue el reformismo militar velasquista (1968-1975). En efecto, los cambios estructurales que aquél gobierno realizó en pocos años impactaron impactó decididamente en los jóvenes que habían nacido entre fines de los años cuarenta e inicios de los cincuenta, y que para entonces o estaban terminando la secundaria o iniciaban sus estudios universitarios. Todo esto, arropado por un contexto internacional sumamente agitado que hacía pensar que los 
cambios radicales eran posibles. Era un tiempo en el que se denunciaban los abusos, la dominación, el colonialismo, el imperialismo, la supervivencia de la injusticia (Cuba, Praga, México, París, los hippies, etc.). Otro horizonte histórico se abría y ahí estaban los jóvenes radicalizados para acelerar los cambios necesarios e ineludibles.

En el Perú el velasquismo, jóvenes de clase media, trabajadores, obreros, campesinos, pobladores, coincidieron en las múltiples agrupaciones políticas de izquierda, lo que se llamó nueva izquierda, que a pesar de su fragmentación participaban presididos por la voluntad de representar políticamente al «pueblo». Cada pequeña agrupación política portaba propuestas más radicales que la otra; $y$ de tanta radicalidad no pudieron calibrar la importancia histórica del velasquismo, lo que los llevó a un enfrentamiento permanente con el gobierno militar. El propio Flores Galindo señalaba que esa nueva izquierda fue muy radical, pero al mismo tiempo sostenía que sin esa radicalidad no hubiera perfilado su identidad. Muchos años después, los dirigentes de esa izquierda evaluarían en tono de auto-crítica su participación política en aquellos años, y confesarían que su sobreideologización les impidió comprender mejor el velasquismo, que hubiera significado otra postura política, quizás con mayores réditos. Como señala Carlos Aguirre (2007), Flores Galindo surgió al interior de una cultura política de izquierda, que giraba sobre temas como la militancia, la organización política, la revolución a la vuelta de la esquina, entre otros aspectos. Se trató de un tiempo en el que la izquierda se organizaba por medio de lo que Lewis A. Coser (1999) denominó «instituciones voraces», tema sobre el que volveré más adelante.

\section{La cultura, la izquierda y el historiador-ideólogo}

Es cierto, había una cultura política de izquierda que al mismo tiempo fue constituyendo a esa misma izquierda política, y viceversa. Pero estando de acuerdo con lo señalado por Aguirre, ampliaría más su idea señalando que no solo era una cultura política sino que era cultura en términos generales. En efecto, se trató de un tiempo en el que se desplegó una serie de manifestaciones culturales como la literatura, el teatro, la música, el periodismo, la caricatura política, el cine, entre otras, que en su conjunto envolvieron, y se enriquecieron al mismo tiempo, con la definición política de izquierda.

Como el propio Aguirre sostiene, Flores Galindo revaloró profundamente la palabra impresa mediante su obsesivo deseo de poner sobre el papel sus ideas, investigaciones y reflexiones de coyuntura, sea por medio del ensayo, del artículo en revistas de divulgación o periodísticos, de sus colaboraciones en suplementos culturales, en libros, etcétera. Para nuestro historiador, la escritura era un arma de la política, el intelectual en tanto ideólogo debía contribuir con el proyecto político: las ideas en favor de la acción. Un claro ejemplo de esta concepción son sus escritos en los que analiza las 
figuras de Mariátegui y Haya de la Torre, y la defensa que realiza de Mariátegui ante las acusaciones del líder aprista de ser «solo un intelectual».

Se sobrentiende, por sus argumentaciones, que en nuestro historiador el intelectual es una figura menor en comparación al político, a no ser que cumpla, como hemos dicho el papel de ideólogo. Entonces, no es exagerado considerar que, al reflexionar sobre Mariátegui, Flores Galindo de alguna manera estaba hablando de sí mismo. Si bien de joven militó en Vanguardia Revolucionaria y en el Movimiento de Izquierda Revolucionaria, y que, posteriormente, sería cercano al Partido Unificado Mariateguista, su papel siempre fue el de proveer ideas a la política de izquierda. Esa era su auto-asignada función social. Como ha señalado un investigador argentino, Manuel Martínez (s/f), Flores Galindo «era un renombrado profesor, ensayista y periodista, un académico no academicista, un militante no partidarizado de la causa por el socialismo».

Un claro ejemplo de los aspectos mencionados se puede hallar en el que es - en mi opinión - el mejor libro de Flores Galindo. Me refiero a La agonía de Mariátegui (1980). Lo escribió en el contexto de la constitución y fracaso de Alianza Revolucionaria de Izquierda, tratando de influir en los debates y definiciones ideológicas de la propia izquierda. Por otro lado, en sus páginas el personaje parece tener vida, el lector siente que es parte de su contexto, comprende las relaciones personales, sociales y políticas de los involucrados, las razones de sus desavenencias. En dicho sentido, este libro es fascinante. Su escritura, que también se lució en el periodismo, es seductora (Cisneros, 1988).

Tomando como herramientas de análisis el psicoanálisis y las mentalidades, Flores Galindo describe la vida cotidiana de un Mariátegui que lucha sin tregua en varios frentes, así como nos describe su mundo cultural para ubicar y comprender su comportamiento político y definiciones ideológicas. Es decir, no asume como determinantes el contexto ni las estructuras, sino que, a partir del personaje y de aspectos usualmente considerados irrelevantes por ser marginales (como las anécdotas), va comprendiendo la totalidad de la vida social. Este libro tuvo varias reediciones y la propia escritura se vuelve en un vehículo protagónico de la argumentación. ¿Cuánto de lo explicado sobre Mariátegui tiene de autorreferencia? Queda a otros especialistas internarse en este tópico. ${ }^{5}$

La palabra hablada también fue utilizada por Flores Galindo con profusión, y siempre en función de cumplir con su papel de ideólogo-historiador. Aparte de las clases universitarias, dedicó tiempo y esfuerzo en participar en coloquios, mesas redondas, debates y especialmente en diálogos con diferentes sectores sociales. Esto último tuvo un impulso fundamental cuando a mediados de los años ochenta funda con Gonzalo Portocarrero, Inés García, Nelson Manrique y otros el centro Socialismo, Utopía y Revolución-SUR, su revista Márgenes y las universidades populares. Por medio de estas,

5 Solo deseo agregar una información adicional: el primero que se refirió a la agonía de Mariátegui fue Luis Alberto Sánchez (1930) en su recuerdo homenaje al poco tiempo de fallecido el Amauta y que fue publicado en la revista Presente. 
Flores Galindo dio innumerables charlas-diálogos a trabajadores a los que también sabía escuchar y con quienes interactuaba permanentemente. Un ejemplo es el prólogo que redactó a las memorias del gran líder sindical desde los tiempos de Mariátegui: Julio Portocarrero (1987), que recogió Rafael Tapia.

Por otra parte, con Gonzalo Portocarrero estimuló estudios en los que ligaba las ciencias sociales con el psicoanálisis y el estudio de las mentalidades. Siempre teniendo como referencia la vida y obra de Mariátegui; hacia sus últimos ańos de vida dedicaría importantes páginas destinadas a comprender la obra de José María Arguedas.

\section{Lectura del Perú desde la utopía andina}

Para entonces ya había empezado a trabajar con Manuel Burga el tema de la utopía andina. A Burga (2019) lo había conocido a mediados de los años setenta en las reuniones promovidas por Pablo Macera. Sus coincidentes puntos de vista e intereses intelectuales se afianzaron en Francia y su colaboración mutua dio a luz un libro que se convirtió en indispensable para entender las primeras décadas del siglo XX: Apogeo y crisis de la República Aristocrática, de 1980.

La utopía andina (Buscando un Inca, de 1986) se vuelve para Flores Galindo en una clave para legitimar la idea de la revolución, una revolución liberadora. Como contraposición, no valora la democracia representativa, lo que llevó a una lectura errada o intencionada ideológicamente de sus críticos, a vincularlo con el senderismo que remecía la vida nacional. Considera que todo el sistema ha fracasado y que no quedaba otra alternativa que su sustitución total. Hay que recordar el trasfondo de la realidad peruana de ese entonces, años ochenta, en la que Sendero Luminoso principalmente había puesto contra las cuerdas la legitimidad de la constitucionalidad, y la respuesta represiva había quedado como la casi única alternativa del orden. Es decir, la lógica política prácticamente había desaparecido para ser sustituido por la lógica de la guerra. En estas condiciones, mantener la idea de la vigencia revolucionaria era un riesgo político y académico. Considero que Flores Galindo defendió la idea revolucionaria pero no al senderismo, como han interpretado algunos analistas.

[...] equipado con las teorizaciones que fue ganando a su registro, relacionadas a los anhelos, las ideas, los mitos, las mentalidades y, en general, a la subjetividad, nuestro autor identificará un hecho, el mundo de las creencias y pasiones de los subalternos, la utopía andina, como una de las variables principales que concurren en la producción de los actos de resistencia, rebelión y revolución en el Perú (Ruiz Zevallos, 2011, p.39). 
En Flores Galindo, la utopía andina no significaba volver al pasado, pero sí se sostenía en el mundo andino y campesino que era justamente el que resistía las embestidas de la subversión y de la represión.

Flores Galindo urgió a la izquierda a evitar el dogma e imaginar posibilidades creativas para la acción política. Con su enfoque sobre cómo los pueblos andinos, entre otros, concibieron o inventaron a los Incas para repensar y cambiar el presente, Buscando un Inca abordó temas clave de la izquierda a la vez que llevaba el debate hacia la historia y hacia las preguntas sobre identidad, imaginario y representación. Flores Galindo nunca abandonó su misión de revitalizar el marxismo y arrebatárselo de las manos de aquellos que lo vieron como una doctrina fundamentalista en lugar de una herramienta creativa para la interpretación y el cambio. A la vez que cuestionaba el eurocentrismo, buscó usar el marxismo y otras escuelas de pensamiento teórico para interpretar y transformar el Perú (Aguirre y Walker, 2019, p. 186).

Buscando un Inca se convirtió rápidamente en un libro fundamental en su momento y de trascendencia internacional, pues recibió el Premio Casa de las Américas en 1986. Parte de su cautivación consiste en que se trata de una obra que busca leer integralmente la historia peruana, pretensión que había sido postergada en las ciencias sociales. Con este libro, Flores Galindo se convertiría en un historiador-ideólogo central en los debates sobre la realidad nacional. Paralelamente, como mencioné, ya había iniciado sus estudios sobre José María Arguedas — en el que veía la posibilidad del socialismo desde la herencia colectivista andina-, pero la enfermedad que ya lo aquejaba no daría tregua hasta su muerte ocurrida en 1990 .

Como ha sucedido en otros momentos de nuestra historia, la muerte de Flores Galindo impidió el desarrollo de una polémica que prometía ser decisiva dentro de los linderos de la izquierda peruana (Gonzales, 2012; La Mula, 2012). En efecto, Degregori había estado preparando un texto de réplica cuestionando la idea de la utopía andina para contraponer la fuerza del mito del progreso, al mismo tiempo que reevaluar la idea de la revolución para sostener una posición política más cercana a la socialdemocracia. Pero, como señalé, la muerte de Flores Galindo ocluyó el debate, como había sucedido a fines de los años veinte entre Mariátegui y Víctor Andrés Belaunde, entre 7 ensayos y lo que sería La realidad nacional. Lamentablemente, la muerte del Amauta impidió que viera la integralidad de la respuesta del socialcristiano y elaborara su contra réplica.

Por su parte, José Luis Rénique se lamenta de otra polémica que no fue la de Flores Galindo con Mario Vargas Llosa:

Vargas Llosa y Flores Galindo jamás debatieron directamente. Sus mundos se tocaron solo tangencialmente. Cuando Flores Galindo terminaba la universidad, Vargas Llosa 
era ya un escritor consagrado y llevaba varios años viviendo en Europa. En 1987, Vargas Llosa se convertiría en líder político nacional al encabezar la protesta contra la nacionalización del sistema financiero decretada por el gobierno de Alan García. Flores Galindo era por ese entonces un modesto y respetado profesor universitario. Buscando un Inca era ya uno de los libros más influyentes publicados en el Perú en la última década. En 1989, Vargas Llosa fue ungido como candidato presidencial de la derecha peruana. Durante su campaña, sus planteamientos llegarían a todo el país a través del aparato propagandístico más formidable visto en la historia electoral del Perú. Enfermo, Flores Galindo luchaba por prolongar su vida. Su infortunio dejó ver el aprecio que su figura despertaba, tanto en el Perú como en círculos académicos extranjeros. Una espontánea campaña económica permitió su traslado a un hospital de Nueva York. Un oasis de solidaridad en un tiempo de rupturas y recelos (Rénique, 1997). ${ }^{6}$

Degregori guardó, por respeto, su texto, y solo lo hizo circular entre algunos amigos. Se aplazó un debate que pudo tener alto vuelo en cuanto a la comprensión del momento nacional y a lo que debería ser la actuación de la izquierda. El texto de Degregori solo se conocería varios años más tarde, cuando sus ańos finales se precipitaban (moriría en 2011). No obstante, y para agravar las consecuencias en la indefinición de la izquierda, ese debate aplazado no continuaría por medio de otros intelectuales. Es más, como se lamenta Ricardo Portocarrero (2007), hoy casi nadie lee a Flores Galindo. ¿Por qué?

\section{El intelectual y «su público»}

Sin pretender encontrar la respuesta definitiva solo alcanzo las siguientes dos ideas.

Una primera es el auditorio que Flores Galindo definió como el prioritario. Como ideólogo se dirigió básicamente a uno que podía ser identificado como de izquierda o cercano o proclive a sus ideas. Esto va en relación directa a su apuesta, ser el intelectual orgánico de la izquierda y de los trabajadores:

Flores Galindo no solo fue un brillante y prolífico historiador profesional, que practicaba su oficio con rigor y creatividad, sino también un inequívoco y persistente militante de izquierda, un personaje público en el sentido más amplio de la palabra; un colaborador de cuanta aventura periodística y editorial surgiera de entre las filas de la izquierda y, en general, del mundo intelectual; y un agresivo (en el buen sentido de la palabra) publicista

6 Hubo otro amago de polémica, entre Flores Galindo y Hernando de Soto, pero el comentario crítico y polémico («Los caballos de los conquistadores, otra vez», 1987b) que nuestro historiador publicó sobre El otro sendero no encontró réplica en De Soto. 
que no solo supo utilizar todas las posibilidades que ofrecía la cultura impresa, sino que se convirtió él mismo en inspirador y promotor de ella (Aguirre, 2007: 182).

En este marco de acción intelectual-ideológica, se entiende la participación de nuestro escritor en un gran número de publicaciones de izquierda: Vaca Sagrada, Allpanchis, El Caballo Rojo, El Búho, 30 Días, Cultura Popular, La Revista, Los Caminos del Laberinto, Debates en Sociología, El Zorro de Abajo, Revista Andina y la que él mismo fundó: Márgenes. Su público privilegiado era el identificado como de izquierda. Por esta misma razón, criticaba a los intelectuales que si bien eran de izquierda aceptaban colaborar en publicaciones como Debate de Felipe Ortiz de Zevallos. Veía esto casi como una claudicación; sumisión frente al canto de sirenas del orden establecido.

Una segunda idea es el carácter de las propias organizaciones políticas de izquierda que se pueden calificar tomando a Lewis A. Coser (1992), como instituciones voraces. Aguirre sostiene que uno de los rasgos centrales de la cultura política de izquierda fue el «compromiso vital, a tiempo completo» (Aguirre, 2007, p. 173) y que es una de las características que exigen las instituciones voraces, precisamente. Es decir que, aun permitiendo a los militantes la libre locomoción, buscan capturar la mente y el corazón de sus integrantes hasta lograr que su identidad y proyecto de vida se constituyan en exclusiva referencia a esas organizaciones. Así fue la mayoría de partidos de la izquierda y tuvo como máxima y perversa expresión a Sendero Luminoso. Esto ocasionó que Flores Galindo sea solo leído estratégicamente para legitimar un proyecto político.

Así, cuando ese auditorio y esas organizaciones políticas se debilitan y pierden razón de ser, cuando esa izquierda a la que quiso influir casi había desaparecido, la figura y la obra de Flores Galindo pierden su influencia. Lo cual es una injusticia intelectualacadémica, pues sus trabajos contienen una alta calidad explicativa, rigurosidad investigativa aparte de filo ideológico, que legitima su lectura más allá de los predios socialistas. En una época como la nuestra, aparentemente «desideologizada», después de la caída del Muro de Berlín y del predominio de la globalización neo-liberal, su narrativa histórica no encuentra lugar para el debate.

\section{Elementos para definir a un tipo de intelectual}

Para concluir deseo caracterizar brevemente a Flores Galindo en tanto intelectual.

Como he mencionado ya, nuestro escritor es un ideólogo de izquierda que legitima la revolución. De esta manera, para él no hay lugar para otras figuras de intelectuales como el asesor del poder, el que se abstiene de la participación política o el que se convierte él mismo en sujeto que busca alcanzar el poder.

Por otra parte, dentro de la clasificación que propone Edward Shils (1972) sobre las tradiciones culturales, Flores Galindo se ubicaría entre la de tipo populista y la revo- 
lucionaria. Es decir, entiende que los sujetos que encarnan lo mejor de la sociedad son los miembros del pueblo, los trabajadores, los pobres, los excluidos. Al mismo tiempo, considera que la solución al sistema injusto solo puede darse mediante un cambio total de las estructuras, es decir, mediante un acto revolucionario.

En cuanto a qué tipo de visión social expresa Flores Galindo, tomemos la propuesta de Thomas Sowell (1990). Este sostiene que hay básicamente dos tipos de visiones sociales: la restringida y la no restringida. La primera sujeta a los individuos a sus circunstancias sin mayores posibilidades liberadoras, y la segunda, privilegiando a los jóvenes, entiende que los sujetos pueden variar sustancialmente sus condiciones y crear otras nuevas y mejores. Atendiendo a esta somera definición, Flores Galindo calza con esta segunda visión, la no restringida; en esa medida, no habría nada más liberador que la revolución. Tomando las ideas de Raymond Aron (s/f), se puede afirmar que Flores Galindo ejerce la crítica ideológica o histórica, que embate contra la sociedad injusta del presente, en nombre de una sociedad por venir, y trata de esbozar un orden radicalmente distinto, deseable e inevitable: hay en este tipo de crítica un talante de ruptura total con el pasado.

Finalmente, desde los análisis realizados por Roger Chartier (1995), Flores Galindo encarnaría al intelectual de razón privada y no de razón púbica al haber definido su auditorio y misión como intelectual en los términos que hemos descrito.

Poco antes de su muerte, Flores Galindo redactó (dictó) la denominada «Reencontremos la dimensión utópica. Carta a los amigos» en la que, a pesar de la adversidad, mantiene los principios y objetivos que dieron sustento a su vida y obra:

Aunque muchos de mis amigos ya no piensen como antes, yo por el contrario, pienso que todavía siguen vigentes los ideales que originaron al socialismo: la justicia, la libertad, los hombres. Sigue vigente la degradación y destrucción a que nos condena el capitalismo, pero también el rechazo a convertirnos en la réplica de un suburbio norteamericano. En otros países el socialismo ha sido debilitado; aquí, como proyecto y realización, podría seguir teniendo futuro, si somos capaces de volverlo a pensar, de imaginar otros contenidos. Esto no es la moda. Es ir contra la corriente. También debemos enfrentarnos a los cultores de la muerte o de aquellos que sólo piensan en repetir las recetas de otros países. El desafío creativo es enorme. (¿Podremos?) (1989).

Alberto Flores Galindo encarnó las aspiraciones de su generación. La evolución posterior de la vida política y social del Perú pondría nuevos retos para el pensamiento socialista y para el papel del propio intelectual. Dejó preguntas y cuestionamientos que aún no han sido resueltos. 


\section{Referencias}

Aguirre, C. (2007). Cultura política de izquierda y cultura impresa en el Perú contemporáneo (1968-1990). Alberto Flores Galindo y la formación de un intelectual público. Histórica vol. XXX, núm. 1.

Aguirre, C y Walker, C. (2019). Alberto Flores Galindo: entre la utopía andina y la utopía socialista. AContraCorriente. Una revista de estudios latinoamericanos vol. 16, núm. 2 https:// www.academia.edu/38371036/Alberto_Flores_Galindo_entre_la_utop\%C3\%ADa_ andina_y_la_utop\%C3\%ADa_socialista

Aron, R. (s/f). El opio de los intelectuales. Buenos Aires: Ediciones El Leviatan.

Burga, M. (2019). Homenaje: Alberto Flores Galindo es recordado por el historiador Manuel Burga. El Comercio, Lima, 28 de mayo.

Burga, M. (2010). Alberto Flores Galindo. Cartas de Francia, 1973-1974. Lima: SUR, Casa de Estudios del Socialismo, Asamblea Nacional de Rectores.

Burga, M. (2005). La historia y los historiadores en el Perú. Lima: Fondo Editorial de la Universidad Nacional Mayor de San Marcos.

Burga, M. (1979). Apogeo y crisis de la República aristocrática (con Alberto Flores Galindo). Lima: Rickchay Perú.

Cisneros, A. (1988). Tito Flores, periodista. Alberto Flores Galindo. Tiempo de plagas. Lima: Ediciones El Caballo Rojo.

Coser, L. (1999). Las instituciones voraces. México DF: Fondo de Cultura Económica.

Chartier, R. (1995). Espacio público, critica y desacralización en el siglo XVIII. Los orígenes culturales de la Revolución francesa. Barcelona: gedisa

Degregori, C. (2005). Alberto Flores Galindo. Otro mundo es posible. Libros \& Artes: Revista de cultura de la Biblioteca Nacional del Perú núm. 11, setiembre.

Flores, A. (1989). Reencontremos la dimensión utópica. Carta a los amigos, Lima, 14 de diciembre https://marxismocritico.com/2016/01/08/reencontremos-la-dimension-utopica/

Flores, A. (1987a). La generación del 68: ilusión y realidad. Márgenes. Encuentro y debate núm. 1

Flores, A. (1987b). Los caballos de los conquistadores, otra vez. Tiempo de Plagas. Lima: Ediciones El Caballo Rojo

Flores, A. (1986). Buscando un Inca: Identidad y utopía en los Andes. La Habana, Cuba: Ediciones Casa de las Américas

Flores, A. (1984). Aristocracia y Plebe. Lima, 1760-1830. Estructura de Clases y Sociedad Colonial. Lima: Mosca Azul editores

Flores, A. (1982). El poder: un viejo debate. Socialismo y Participación núm. 20

Flores, A. (1980). La agonía de Mariátegui. La polémica con la Komintern. Lima: Desco

Flores, A. (1976). Arequipa y el sur andino, Ensayos de Historia regional, Siglos XVIII-XX. Lima: Editorial Horizonte 
Flores, A. (1974). Los Mineros de la Cerro de Pasco. Lima: Pontificia Universidad Católica del Perú.

Gonzales, O. (2012). Alberto Flores Galindo y Carlos Iván Degregori: La polémica desplazada. Crónicas Urbanas núm. 17.

Gonzales, O. (1999). Señales sin respuesta. Los zorros y el pensamiento socialista en el Perú (19681989). Lima: Ediciones Preal.

Gonzales, O. (1996). Sanchos fracasados. Los arielistas y pensamiento político peruano. Lima: Ediciones Preal.

Mannheim, K. (1952). The problem of generations [1927/1928], Essays on the Sociology of Knowledge. New York: Oxford University Press.

Manrique, N. (2005). Alberto Flores Galindo, cambiar el mundo, cambiar la vida. Libros \& Artes: Revista de cultura de la Biblioteca Nacional del Perú núm. 11, setiembre.

Martínez, M. (s/f). Recuerdo de Alberto Flores Galindo, Tito (1949-1990). Herramienta. Revista de debate y critica marxista. https://herramienta.com.ar/articulo.php?id=2317

Mula,La.(2012).DebateinconclusoentreTitoFloresGalindoyCarlosIvánDegregori.https://lamula. pe/2012/05/22/debate-inconcluso-entre-tito-flores-galindo-y-carlos-ivan-degregori/ despernado/

Portocarrero, G. (2005). La hazaña como deber: perfil de Alberto Flores Galindo. http:// www.librosperuanos.com/autores/articulo/00000000478/La-hazana-como-deber-perfilde-Alberto-Flores-Galindo

Portocarrero, R. (2007). Alberto Flores Galindo: la historia, la política y el socialismo. Ciberayllu. 6 de mayo. http://www.ciberayllu.org/Comentario/RP_FloresGalindo.html

Portocarrero, J. (1987). Sindicalismo Peruano: Primera Etapa, 1911-1930. Prólogo por Alberto Flores Galindo. Lima: Editorial Gráfica Labor.

Ragas, J. y Valdez, J. (2009). La vigencia de la Utopía: a 20 años de la muerte de Alberto Flores Galindo, jueves 19 de marzo. https://puntoedu.pucp.edu.pe/entrevistas/ la-vigencia-de-la-utopia-a-20-anos-de-la-muerte-de-alberto-flores-galindo/

Rénique, J. (1997). Flores Galindo y Vargas Llosa: un debate ficticio sobre utopías reales. Ciberayllu.10 defebrero.http://www.andes.missouri.edu/andes/Historia/JLR_Utopias.html

Rochabrún, G. (2007). Batallas por la teoría En torno a Marx y el Perú. Lima: Instituto de Estudios Peruanos.

Ruiz, A. (2011). Alberto Flores Galindo: marco sociopolítico, fronteras y proyecto político. Histórica vol. XXXX, núm. 1.

Sánchez, L. (1930). Datos para una semblanza de J. Carlos Mariátegui. Presente. Periódico Inactual núm. 1, julio.

SHILs, E. (1972). The intellectuals and the powers, and other essays. The University of Chicago Press.

Sowell, T. (1990). Conflicto de visiones, Buenos Aires: Gedisa. 